\title{
Hegemonic Gender Norms and the Gender Gap in Achievement: The Case of Asian Americans
}

\author{
Amy Hsin \\ Queens College, City University of New York
}

\begin{abstract}
Many argue that hegemonic gender norms depress boys' performance and account for the gender gap in achievement. I describe differences in the emergence of the gender gap in academic achievement between white and Asian American youth and explore how the immigrant experience and cultural differences in gender expectations might account for observed differences. For white students, boys are already underperforming girls in kindergarten, with the male disadvantage growing into high school. For Asian Americans, boys perform as well as girls throughout elementary school but begin underperforming relative to girls at the transition to adolescence. Additionally, I show that the Asian American gender gap is larger in schools with stronger male-centric sports cultures and where boys' underachievement is normalized. I speculate that model-minority stereotypes, the immigrant experience, and standards of masculinity that promote pro-school behaviors in boys act as protective factors in early childhood but wane at the transition to adolescence during a period when the dominant peer culture plays a larger role in shaping gender identities. The study offers evidence that the gender gap in achievement is not an inevitable fact of biology but is shaped by social environment.
\end{abstract}

Keywords: education; gender; Asian Americans; gender norms; culture

Citation: Hsin, Amy. 2018. "Hegemonic Gender Norms and the Gender Gap in Achievement: The Case of Asian Americans." Sociological Science 5: 752774.

Received: July 22, 2018

Accepted: October 23, 2018

Published: December 3, 2018

Editor(s): Jesper Sørensen, Sarah Soule

DOI: $10.15195 / \mathrm{v} 5 . a 32$

Copyright: (C) 2018 The Author(s). This open-access article has been published under a Creative Commons Attribution License, which allows unrestricted use, distribution and reproduction, in any form, as long as the original author and source have been credited. (0)(1)
THE gender gap in education favoring females is so pervasive that it is popularly 1 referred to as the "problem with boys." The origins of this phenomenon are still debated. Hegemonic masculinity, a system of beliefs and practices that simultaneously valorize dominance, athleticism, and physical strength and denigrate conscientiousness and diligence in males, is speculated to depress the academic engagement and achievement of boys (Archer, Pratt, and Phillips 2001; Connell and Messerschmidt 2005; Legewie and DiPrete 2012; DiPrete and Buchmann 2013). Identifying the effect of gender norms on the gender gap in academic achievement, however, is difficult because credible sources of exogenous variation are necessary to isolate their effects, yet sources of variation are difficult to find because norms are, by definition, widely held beliefs.

The case of Asian Americans offers a unique opportunity to assess the role of gender norms in shaping academic achievement. As immigrants or the children of immigrants, Asian American youth are not only influenced by the dominant gender expectations in the United States but also by the norms and expectations of their countries of origin. Immigrants are self-selected in terms of their optimism and belief that their hard work will yield positive outcomes (Kao and Tienda 1998; Hsin and Xie 2014). Asian immigrant parents hold higher educational expectations for their children than white parents (Goyette and Xie 1999). In contrast to hegemonic standards of masculinity, dominant concepts of masculinity in many Asian countries are more fluid and promote qualities such as conscientiousness, gentleness, 
and patience in boys (Sung 1987; Chua and Fujino 1999). The protective effects of immigration and Asian cultural norms may wane at the transition to adolescence during a period when peers and peer culture play a relatively larger role in shaping gender identities. Model-minority stereotypes may be more damaging to adolescent Asian American boys' developing sense of self (than they are to adolescent Asian American girls'), which may have negative consequences for boys' academic performance.

In this article, I use the case of white and Asian American youth to explore the role of norms in shaping the gender gap in achievement. I begin by describing racial/ethnic differences in the emergence of the gender gap in achievement. To do this, I follow Hsin and Xie (2014) by combining two national cohort studies, the Early Childhood Longitudinal Study, Kindergarten Cohort (ECLS-K) and the Education Longitudinal Study (ELS), to describe disparities in achievement from kindergarten through high school. I extend the work of Hsin and Xie (2014) to explicitly explore trends in the gender gap and the role of peer norms and school environment in shaping the gender gap in achievement among Asian Americans once it emerges in high school.

The article offers three empirical findings. First, in contrast to whites, no gender gap in achievement exists among Asian American students throughout elementary school, but Asian American boys begin underperforming relative to Asian American girls at the transition to adolescence. Second, Asian American girls accrue a larger race premium relative to Asian American boys. Third, Asian American boys are more likely to underperform relative to Asian American girls in schools where the dominant peer culture normalizes boys' underachievement. I speculate on how the immigrant experience, model-minority stereotypes, and cultural differences in gender expectations help explain the empirical findings. Overall, I argue that these findings regarding the gender gap in achievement are not inevitable facts of biology but phenomenon that have origins in the social environment.

\section{Hegemonic Masculinity and the Gender Gap}

The female advantage in academic performance emerges early, when children are in kindergarten (DiPrete and Jennings 2012), and continues into elementary school (Tach and Farkas 2006) and high school (Mickelson 1989; Perkins et al. 2004). In high school, girls elect to take as many rigorous courses in math and the sciences as boys do (Xie and Shauman 2003; Catsambis 2005) and attain higher grades than boys do in all major subjects (Perkins et al. 2004). Scholars have attributed these gender disparities in academic performance to hegemonic gender norms that promote academic engagement for girls but stigmatize them for boys (Legewie and DiPrete 2012). Hegemonic ideals of femininity praise qualities such as cooperation, conscientiousness, and attentiveness in girls (Connell and Messerschmidt 2005). These qualities help bolster girls' academic performance because they are rewarded by schools and teachers (Downey and Vogt Yuan 2005; DiPrete and Jennings 2012). In contrast, hegemonic masculinity exalts qualities such as dominance and athleticism while denigrating diligence and conscientiousness as feminine (Connell and Messerschmidt 2005). Pro-school behaviors, such as effort and diligence, are 
incompatible with "cool" masculinity, which simultaneously valorizes academic success attained through "effortless achievement" and perceives success that is achieved through hard work as being not masculine and "uncool" (Epstein 1998; Archer et al. 2001; Jackson and Dempster 2009).

Boys and girls not only face different gender expectations but the expectations faced by boys are more restrictive than those faced by girls. The gender revolution of the last half-century expanded the standards of femininity to encompass traditionally masculine traits, such as confidence, independence, and rationality. Yet, masculine standards remain relatively unchanged and narrow (England 2010). For example, far more females have entered previously male-dominant fields of study since the 1970s than males have entered previously female-dominant fields of study in college. Parents are more likely to encourage girls to play with traditional "boy" toys, such as Legos and science sets, than they are to encourage boys to play with dolls. Standards of masculinity are more restrictive than standards of femininity, and the social sanctions faced by males for gender nonconformity are stronger than those faced by females (Pascoe 2007). For example, whereas being called a "tomboy" is now taken as a mark of honor for many girls, being called a "sissy" is still considered universally derogatory for boys.

Gender-typical behaviors matter for the gender gap in achievement because they are correlated with academic performance. Studies show that adolescent boys who report moderate levels of gender-atypical behaviors (e.g., boys who are more emotionally sensitive and less physically athletic) are more academically engaged and do better academically than adolescent boys who confirm to hegemonic gender expectations (Ueno and McWilliams 2010; Yavorsky and Buchmann 2018).

\section{Asian American Educational Expectations and Gender Norms}

Although the research offers evidence that hegemonic gender norms in the United States suppress the academic performance of boys, the case of Asian Americans offers an interesting point of contrast because Asian American youth are exposed to additional norms and gender expectations that may produce different gender patterns in achievement in contrast to their white counterparts.

As immigrants or children of immigrants, Asian American youths' and their parents' orientations toward education are shaped by their immigrant experience. Immigrants are self-selected in terms of motivation and optimism (Kao and Tienda 1998), and Asian American immigrants are more likely than most other immigrant groups to see education as the main vehicle for upward mobility for their children (Sakamoto, Goyette, and Kim 2009). Asian American parents, across all major ethnic subgroups and socioeconomic statuses (SESs), hold higher educational expectations than white parents (Goyette and Xie 1999; Hsin and Xie 2014; Liu and Xie 2016). Many Asian American youth come to see their educational success as redemption for the sacrifice that their parents endured because of immigration and, as a result, are motivated to try harder to meet their parents' high educational expectations (Tran 2016). 
Asian American youth also benefit from "stereotype promise," or the promise of being viewed as academically gifted and hardworking (Lee and Zhou 2015). Stereotype promise bolsters Asian American youths' performance in ways that confirm the positive stereotypes. Hsin and Xie (2014) find that students from all major Asian ethnic subgroups-East Asian, Filipino, South Asian, and Southeast Asian American students-are perceived by teachers to be harder working and more attentive to schoolwork than their white peers.

Standards of masculinity in many Asian countries do not fully align with hegemonic norms in the United States in ways that may benefit Asian American boys' academic performance. Chua and Fujino (1999) find that Asian American males have a less rigid understanding of masculinity than their white peers. Although white males conceive masculinity as oppositional to femininity, both foreign and U.S.-born Asian males conceive masculinity as containing both masculine and feminine traits. White males were also more likely than their Asian American peers to rate qualities such as dominance, independence, and physical strength as strongly correlated with masculine identity. In contrast, Asian American males were more likely than their white peers to considered reliability, caring, and politeness as hallmarks of masculinity.

Unfortunately, the study did not look at variation across Asian ethnic subgroups, so it is unknown to what extent concepts of masculinity vary across ethnic subgroups. However, the contention that standards of masculinity among Asian Americans are more fluid than hegemonic standards is consistent with Confucian teachings, which have shaped cultural norms in East Asian countries. For example, Chinese gender norms generally contrast physical strength and athleticism as oppositional to intellect in the idiom "strong limbs, simple mind" (Sung 1987:114). Confucian teachings also praise qualities such as gentleness, self-cultivation, and work ethic in men and denigrate qualities such as physical strength, aggression, and dominance, which is in stark contrast to dominant gender norms in U.S. society.

\section{Asian American Achievement at the Intersection of Race and Gender}

Feminist theories argue that social identities, such as race and gender, are not experienced in isolation of one another but interact to shape individual experiences (McCall 2005). We might expect Asian American girls to experience their ethnicity differently than Asian American boys.

Racialized and gendered stereotypes that conceive Asian Americans as model minorities have potentially more damaging effects for Asian American boys than Asian American girls. Asian American males are perceived by their non-Asian peers to be intelligent and diligent but also socially inept, unathletic, and sexually undesirable (Eng 2001; Wong et al. 2012). Nearly all adolescent boys in Qin's study of 72 Chinese immigrant adolescents report being harassed for being perceived as weak and nerdy (2009). Despite group heterogeneity, these negative depictions are uniformly and rigidly levied at all Asian ethnic groups (Espiritu 2008) and lower Asian American males' self-image (Wong et al. 2012; Lu and Wong 2013). 
Chen (1999) argues that some Asian American males strike hegemonic bargains to "achieve" masculinity by adopting "compensatory strategies" to undermine negative stereotypes and conform to hegemonic standards. Qin (2009) finds that Chinese boys attempt to fight the stereotype of being "nerds" by excelling in nonacademic activities, such as team sports and video games. Lei (2003) shows that Southeast Asian American adolescent males respond to being perceived as docile and unattractive by "acting tough" and traveling in groups to protect themselves against harassment.

In contrast to boys, the gender expectations that most Asian American girls face align with hegemonic standards and should positively foster their academic performance. Like white girls, Asian American girls are expected to be cooperative and responsible and do well in school (Yip and Fuligni 2002; Suárez-Orozco and Qin 2006). As children of immigrants, they are also socialized to be the "keepers of the culture" and are subjected to greater parental control (Billson 1995). In a study of low-income Vietnamese immigrant families, Zhou and Bankston (2001) show how the combination of traditional gender roles and the immigrant experience push girls to outperform boys. They show that immigrant families come to recognize the importance of having a dual-income household in securing economic mobility and, as a result, demand both sons and daughters to excel in school. Traditional gender roles, however, lead parents to exercise greater control over their daughters' social lives than their sons'. Whereas sons are permitted more liberties, daughters are prevented from socializing and required to devote more time to schoolwork. This pattern of stronger parental control of daughters versus sons coupled with high educational expectations was found across many Asian ethnic groups (Dasgupta 1998; Talbani and Hasanali 2000). For example, Espiritu (2001) shows that Filipino American families expected both daughters and sons to achieve in school, but families exercised stronger control of daughters' morality and sexual loyalties; girls are expected to be "good Filipinas" as opposed to "loose and immoral Americans." Similarly, in a study of Chinese immigrants, Qin (2009) shows that although families expected all children to do well in school, they actively discouraged their daughters from attending parties, spending time with friends outside of school, and bringing "shame" to the family by being sexually promiscuous, whereas they were more permissive with sons.

Overall, the research implies that the effects of race on Asian American girls will differ from the effects of race on Asian American boys because race and gender will interact to shape individual experiences. The combination of hegemonic gender expectations, high parental expectations, and traditional gender expectations that subject the children of immigrants to greater parental control will act to bolster the academic performance of Asian American girls. Thus, they should accrue greater benefits from their racial status than Asian American boys. In contrast, Asian American boys face greater conflicting gender expectations. On one hand, the high parental educational expectations and stereotype promise should serve as protective factors. On the other hand, the social sanctions associated with deviating from dominant gender norms are harsher for boys than for girls. Model-minority stereotypes stigmatize Asian American boys more so than Asian American girls. This should imply that Asian American boys should benefit less from their racial status relative to Asian American girls. Put in other words, the estimated effects 
of gender and race on achievement should be interactive rather than additive, and Asian American girls should accrue larger benefits in academic achievement from their racial status than Asian American boys.

\section{Asian Gender Norms and the Transition to Adolescence}

Gender theories posit that gender is not an immutable trait that people have but something that people "do," or accomplish through repeated interactions across space and time (West and Zimmerman 1987; Morris 2011). How gender is enacted and how individuals are socialized to perform gender is an ongoing process that occurs throughout the life course.

Research in developmental psychology also shows that gender differentiation accelerates at the transition to adolescence and that adolescence, in particular, is an especially tumultuous period for the formation of gender identities because the process occurs at the onset of physical changes in appearance and heightened role expectations (Hill and Lynch 1983). Adolescence is also a time when peer influence grows strongest (Brown, Clasen, and Eicher 1986). As adolescents seek to establish emotional independence from parents, they often look to peers to fill this void and create a sense of belonging (Steinberg and Silverberg 1986). Boys' formation of self-image, in particular, is tied to establishing autonomy and independence (Miller 1991; Gilligan 1996). In contrast, girls maintain relatively stronger emotional connections with family members throughout adolescence.

Immigrant youth face unique challenges in adolescence. They experience the same developmental challenges as white youth but must go through this rite of passage while reconciling differing cultural expectations and gender norms. Immigrant girls are socialized to develop a stronger sense of obligation and loyalty to families, communities, and ethnic cultures compared to boys (Suárez-Orozco and Qin 2006). Immigrant girls are more likely to retain their ethnic identity, choose hyphenated identities, and embrace bicultural identities relative to immigrant boys (Rumbaut 1997; Yip and Fuligni 2002; Suárez-Orozco and Qin 2006). Immigrant boys, on the other hand, have greater difficulty embracing their ethnic identifies (Rumbaut 1997; Suárez-Orozco and Qin 2006). They are more likely to encounter negative racialized experiences, perceive that they are excluded from mainstream society, and distance themselves from parents, family, and immigrant communities. All of these factors increase their risk of academic disengagement.

\section{The Role of Schools in Channeling Gender Norms}

Although hegemonic gender norms are widely shared, how they are evoked and enacted depends on the social and relational context in which they occur (Ridgeway and Correll 2004; Morris 2011). This means that schools are a conduit for how gender norms are manifested in achievement outcomes. Decades of education research show that students are more motivated and work harder when they attend schools that reward academic performance (Coleman 1966; Jencks and Mayer 1990). 
More recent studies show that school environment can play a role in magnifying or mitigating the gender gap in achievement.

Exploiting a quasiexperimental design that randomly assigned students to classrooms, Legewie and DiPrete (2012) demonstrate that the gender gap in test scores is strongly patterned by the SES composition of classrooms and that an important channel through which SES composition affects the gender gap is through boys' academic engagement and work habits. High-SES classrooms foster boys' achievement because achievement and pro-school behaviors are not denigrated as antimasculine. In a different study, Legewie and DiPrete (2014) show that school environments work to favor boys' educational outcomes by influencing boys' major choice in the science, technology, engineering, and mathematics (STEM) fields. Two characteristics of schools-strength of high school curricula in science and math and gender segregation of extracurricular activities-are found to shape girls' decisions to enter STEM fields.

Qualitative studies also emphasize the importance of school context. In particular, they demonstrate how the dominance of sports culture over other forms of educational extracurricular activities shape and reflect concepts of masculinity in schools. Dominant gender norms socialize boys to seek outlets to assert their dominance over girls and other boys. Excelling in sports becomes a way to express hegemonic masculinity by establishing physical strength and toughness (Morris 2008). Even if boys do not belong to sports teams, expressing interest in sporting culture is necessary to avoid being stigmatized as feminine and unmasculine (Pascoe 2007). For example, in a study of two high schools in Ohio, Morris (2008) describes how boys who belong to nonsport clubs, such as band, theatre, or the debate team, were perceived by their peers to be nerds, "pussies," or students who put "too much effort" into school. Qin's study (2009) of Chinese adolescents also found that many boys joined sports teams or cultivated interest in competitive, organized sports as a response to being labeled as nerds or weak. Thus, schools with a strong male-centric sports culture are also environments that normalize hegemonic gender expectations by exalting activities that celebrate athleticism and physical strength and depressing academic engagement and achievement in boys.

Building upon this research, I construct measures to capture two aspects of school context and correlate these measures to the gender gap in achievement among Asian Americans. The first captures the dominance of male sports culture in the school environment. The second measure uses the gender gap in academic performance among white students as a proxy for the dominant gender norms in schools. More than 85 percent of Asian American students in the survey attend school where white students are the racial majority; therefore, white students set the dominant gender norms in schools. A large, white gender gap in grades will indicate schools where boys' academic underperformance is normalized. By contrast, a small, white gender gap in grades will indicate schools where boys' academic achievement is normalized. 


\section{Data and Measures}

\section{Data}

I analyze two national cohort studies to describe trends in the gender gap in achievement through key developmental stages from kindergarten entry through high school. The Early Childhood Longitudinal Study-Kindergarten Cohort (ECLS-K) is used to describe trends in the gender gap from elementary school through middle school. The Education Longitudinal Study (ELS) is used to describe trends in the gender gap through high school. The ECLS-K is a cohort study of students who entered kindergarten in 1998 and were interviewed again in grades 1, 3, 5, and 8. More than 20,000 kindergarten children were randomly drawn from about 1,000 public and private schools. The ELS is a cohort study of more than 15,000 10th graders drawn from about 750 schools in 2002 with follow-up interviews in 2004 and 2006. Both surveys used a two-stage sampling method with schools as primary sampling units. Both surveys oversampled Asian Americans.

For both cohort studies, I restrict my analytical sample to cases that participated in all survey waves. Specifically, for the ECLS-K, the sample was restricted to only students who were continuously followed from kindergarten to eighth grade. For the ELS, the sample was restricted to only students who were followed from base year (10th grade) to 11th grade. Furthermore, I analyze a balanced sample of Asian American and white students. White students who attend schools in which an Asian American student is not also surveyed are excluded from the sample. Sampling weights provided by ECLS-K and ELS were used when appropriate. The final analytical sample is 5,716 white students and 513 Asian American students for the ECLS-K and 3,516 white students and 1,204 Asian American students in the ELS. Of these cases, about 25 percent had missing values on at least one variable. Multiple imputations are used to handle cases with missing values on any of the variables used in the analysis. All analyses were also conducted by using listwise deletion to handle missingness. There were no substantive differences in findings.

The sample of Asian Americans in the ELS is large enough to conduct additional analysis by Asian ethnic groups. Ethnic subgroups that are analyzed are East Asian $(\mathrm{N}=503)$, Filipino $(\mathrm{N}=152)$, Southeast Asian $(\mathrm{N}=361)$, and South Asian $(\mathrm{N}=188)$ American. East Asian Americans include students who self-identified as Chinese, Japanese, or Korean.

\section{Measures}

The main dependent variable is students' academic achievement. I focus on grades over test scores because grades, particularly high-school grades, are more predictive of later academic success than standardized test scores and because grades not only capture cognitive abilities but also behaviors and orientation learned early in life that tend to persist into high school and college (DiPrete and Buchmann 2013). The behaviors and orientation captured by grades include demonstrating effort, completing homework on time, being prepared for class, and being alert and attentive (Hsin and Xie 2014; DiPrete and Jennings 2012). 
In the ECLS-K, academic achievement is measured by teachers' ratings of students' proficiency in reading, math, and general knowledge and/or science by using the academic rating scales (ARSs). According to the National Center for Education Statistics (NCES), ARSs are teachers' assessments of students' mastery of skills and the strategies students develop to read, solve math problems, and investigate scientific phenomena. Teachers rate students on a five-point scale from "not yet" to "proficient." I construct a composite measure of academic achievement using these three ARS measures by first standardizing all three measures to have a mean of zero and a standard deviation of one and then taking their unweighted average. Academic achievement in high school (using the ELS data) is measured by using grade point average (GPA) for each grade from ninth to 12th. High school grade point average is comparable to ARS scores for lower grades in the ECLS-K because both capture assessments of students' mastery of specific academic tasks as well as teachers' subjective evaluations of students' progress and performance. Like ARS scores, high school GPA is standardized to have a mean of zero and standard deviation of one.

Dominant gender norms in schools are measured by (1) dominance of malecentric sports culture and (2) the white gender gap in achievement. To measure male-dominance sports culture in schools, I construct a ratio of male-only to femaleonly extracurricular sports activities offered by each school. I then create a dummy variable indicating if the school offers more than 50 percent male-only extracurricular sports activities. The white gender gap is measured as the difference between the average GPA among white girls and the average GPA of white boys in each school. To ensure correct causal ordering, the variables used to measure school environment are measured in 10th grade, and the dependent variable, GPA of Asian American students, is measured in 11th grade.

The key independent variables are race and gender. In the ECLS-K, parents were asked about the race of their children. Parents were given five racial categories to choose from: white, black, Asian American, native Hawaiian, or American Indian. In the ELS, race is derived from student self-reports across seven racial categories: white, non-Hispanic, black, Hispanic, Asian American, Native Hawaiian and/or Pacific Islander, and American Indian. Among those who identified as Asian American, students were further asked to identify as one of the following: Chinese, Filipino, Japanese, Korean, Southeast Asian, or South Asian American. Gender is a dummy variable indicating if the target student is female. Additional controls for individuals, families, and schools are also included. Individuals and family controls include parental educational expectations, family SES, generational status, number of siblings, single-head household, and mother's age. School controls include total enrollment, school type (public, religious, or private), region (urban, rural, or suburban), percentage who qualify for free lunch, percentage of graduating class set to attend college, and percentage of student body speaking English as a second language. The full list of variables is listed in Table 1.

Finally, I consider how school context might affect the gender gap in academic performance through students' academic engagement. Academic engagement is measured by using teacher reports of students' motivation and attentiveness. In the ELS, math and reading teachers were asked two questions on students' work habits 
Table 1: Description of variables.

\begin{tabular}{|c|c|}
\hline Variable & Description \\
\hline \multicolumn{2}{|c|}{ Early Childhood Longitudinal Survey-Kindergarten Cohort (ECLS-K) } \\
\hline \multicolumn{2}{|l|}{ Outcome variable } \\
\hline Academic achievement & Academic rating scales (standardized) \\
\hline \multicolumn{2}{|l|}{ Individual and/or family controls } \\
\hline Female & $0=$ male $; 1=$ female \\
\hline Race & 0 if white; 1 if Asian American \\
\hline Family SES & Composite measures of family socioeconomic status (standardized) \\
\hline Generational status & $\begin{array}{l}\text { Categorical: first, second, and third generation and beyond } \\
\text { (reference) }\end{array}$ \\
\hline \multicolumn{2}{|l|}{ Number of siblings } \\
\hline Single headed household & $0=$ two-parent household; 1 = single-parent household \\
\hline \multicolumn{2}{|l|}{ Mother's age } \\
\hline \multirow{2}{*}{\multicolumn{2}{|c|}{ Outcome variable }} \\
\hline High-school GPA & \\
\hline Academic motivation & $\begin{array}{l}\text { Teacher ratings of students' work ethic and motivation } \\
\text { (standardized) }\end{array}$ \\
\hline $\begin{array}{l}\text { Parental educational } \\
\text { expectation }\end{array}$ & $\begin{array}{l}\text { Highest education level parents expect children will attain } \\
\text { (standardized) }\end{array}$ \\
\hline \multicolumn{2}{|l|}{$\begin{array}{l}\text { School environment and/or peer } \\
\text { culture }\end{array}$} \\
\hline White boys' achievement & Average grade point average of white boys within each school \\
\hline White gender gap & $\begin{array}{l}\text { Differences in grade point average between white boys and } \\
\text { girls within each school }\end{array}$ \\
\hline \multicolumn{2}{|l|}{ Individual and/or family controls } \\
\hline Past achievement & Ninth-grade grade point average \\
\hline Female & $0=$ male $; 1=$ female \\
\hline Race & 0 if white; 1 if Asian American \\
\hline Family SES & $\begin{array}{l}\text { Composite measures of family socioeconomic status } \\
\text { (standardized) }\end{array}$ \\
\hline Generational status & $\begin{array}{l}\text { Categorical: first, second, and third generation and beyond } \\
\text { (reference) }\end{array}$ \\
\hline \multicolumn{2}{|l|}{ Number of siblings } \\
\hline Single headed household & $0=$ two-parent household; 1 = single-parent household \\
\hline \multicolumn{2}{|l|}{ Mother's age } \\
\hline \multicolumn{2}{|l|}{ School controls } \\
\hline Enrollment & Total enrollment \\
\hline School type & Categorical: public (reference), Catholic, and private \\
\hline Region-urban & Categorical: suburban (reference), urban, and rural \\
\hline$\%$ free lunch & Percentage of 10th-grade class qualifying for free lunch \\
\hline$\%$ attend college & Percentage of 2003 graduates who attended 4-year college \\
\hline$\%$ English as a second language & Percentage of student body is not English proficient \\
\hline
\end{tabular}

and motivation. The first question asked teachers to rate students in terms of their attentiveness on a four-point scale ranging from "never attentive" to "attentive all the time." The second question asked teachers whether they agreed or disagreed that the student works hard for their grades. Responses to these two questions were combined by using an additive index with each response assigned equal weights. This additive index is standardized to have a mean of zero and a standard deviation of one. 


\section{Analytical Strategy}

\section{Estimating the Effect of Gender Norms from Kindergarten to 12th Grade}

The ECLS-K and ELS are combined to create a synthetic cohort. Such an approach means that the longitudinal structures of the two data sets are lost. The benefit to this approach is that the two data sets can be combined to describe trends in the gender gap in achievement from kindergarten to high school. To account for potential selection into schools between Asian American and white students and, to a lesser extent, between boys and girls, I estimate school fixed-effect regressions. ${ }^{1}$ For each grade level, the following school fixed-effect regression is estimated to obtain within-school comparisons:

$$
Y_{i s}=\beta_{0}+\beta_{1} \text { Asian }_{i s}+\beta_{2} \text { Female }_{i s}+\beta_{3} \text { Asian }_{i s} * \text { Female }_{i s}+\eta_{s}+\varepsilon_{i s}
$$

where $\mathrm{Y}_{i s}$ represents academic achievement for child $i$ in school $s$. Female ${ }_{i s}$ is a gender dummy. Asian ${ }_{i s}$ is a race dummy. $\beta_{3}$ is a race-sex interaction term. In this specification, white males are the reference category to which all other groups are compared. Factors that differ across schools-such as rigor of coursework, teacher quality, and the socioeconomic composition of schools-are all captured by school-level fixed-effect $\eta_{r s}$. The residuals are represented by $\epsilon_{i r s}$.

To describe trends in the gender gap, I plot trends in the predicted achievement scores from equation (1) by race and gender to assess whether the Asian American gender gap is smaller than the white gender gap in early childhood and whether the Asian American gender gap widens into adolescence. Next, I focus on the race-sex interaction term $\beta_{3}$ in equation (1) to determine whether the effects of race and gender are interactive or additive. If $\beta_{3}=0$, then the effect of race and gender is purely additive. In this case, $\beta_{1}$ entirely captures the race premium associated with being Asian American, and $\beta_{2}$ entirely captures the gender premium associated with being female. Additive effects of race and gender mean that Asian American boys and Asian American girls will experience the same race premium, $\beta_{1}$, and the only academic advantage Asian American girls will have over Asian American boys is $\beta_{2}$. If $\beta_{3}>0$, then the effect of race and gender are interactive. $\beta_{3}>0$ implies that the total advantage of Asian American girls over Asian American boys is $\beta_{2}+\beta_{3}$, where $\beta_{2}$ is the gender premium associated with being female and $\beta_{3}$ is the additional race premium Asian American girls accrue over Asian American boys. Under the scenario of interactive race and gender effects, Asian American girls will accrue a larger race premium than Asian American boys. ${ }^{2}$

\section{Estimating School Effects on the Asian American Gender Gap}

To evaluate whether the dominant gender norms embedded in schools affect the Asian American gender gap in achievement, I estimate the following model using linear regressions:

$$
Y_{i s}=\beta_{0}+\beta_{1} \text { Female }_{i}+\beta_{2} \text { Peers }_{S}+\beta_{3} \text { Female }_{S} * \text { Peers }_{i}+\beta_{4} \mathbf{X}+\beta_{4} \mathbf{S}+\varepsilon_{i s}
$$


where $i$ and $s$ are indices for individuals and schools. $Y_{i s}$ represents the GPA of Asian American students. Peers ${ }_{s}$ represents the dominant gender norms in school $s$, which is measured by (1) the average grade point average of white boys and (2) the white gender gap in achievement. $\mathbf{X}$ and $\mathbf{S}$ are vectors of control variables for individuals and school characteristics. In order to model school context effects, I move from estimating within-school effects to a cross-sectional analysis on the pooled sample of Asian American students. Because the Asian American gender gap only emerges in high school, analyses of school effects will exclusively use the ELS data. All analyses adjust for clustering at the school level.

Studies seeking to estimate unbiased estimates of school effects on achievement must contend with the differential selection of families into schools. For example, if more motivated parents were more likely to send their children to better-quality schools, then the estimated effect of schools on achievement would be biased. Because the goal of this study is to estimate the effect of schools on the gender gap in achievement, bias is introduced only if boys and girls systematically attended different types of schools. For example, the estimated effect of schools will be biased if more motivated parents were more likely to send sons to more gender-egalitarian schools and daughters to less egalitarian schools. Table 2 presents select sample statistics by the school environment measures. The results show that families of Asian American youth attending schools with large, white gender gaps tend to be more disadvantaged than families of Asian American youth attending schools where the white gender gap is low. Parents of Asian American youth who attend schools with high-performing white boys also tend to have higher educational expectations for their children. The critical point, however, is that Asian American girls and boys do not differ in terms of their propensity to attend schools with a lower or higher white gender gap in achievement or average GPA of white boys. This offers evidence that differential selection by gender is an unlikely source of bias.

\section{Results}

\section{The Gender Gap in Achievement from Kindergarten to 12th Grade}

Figure 1 and 2 plot the predicted achievement scores from unadjusted school fixedeffect models for whites and Asian Americans, respectively. The point estimates that are plotted by these graphs are presented in Table 3. Figure 1 shows that among white students, the gender gap in achievement is already present at kindergarten entry. At the start of kindergarten, girls are already outperforming boys by 0.12 standard deviations (Table 3). This difference grows to 0.18 standard deviations by eighth grade and 0.35 standard deviations by 11th grade (Table 3 ). The growing disparity between white boys and white girls is primarily attributed to the increasing underperformance of white boys relative to white girls in adolescence.

The Asian American gender gap in achievement follows a different pattern. Figure 2 shows that no significant gender gap in achievement exists throughout elementary school for Asian Americans. No Asian American gender gap exists in early-to-middle childhood because Asian American boys are not underachieving 
Table 2: Select descriptive statistics by school environment, 11th-grade ELS.

\begin{tabular}{lcccc}
\hline & \multicolumn{2}{c}{$\begin{array}{c}\text { Gender gap in } \\
\text { achievement (white) }\end{array}$} & \multicolumn{2}{c}{ Average GPA of white } \\
boys
\end{tabular}

Note: Data source is the ELS. "High" refers to schools with gender gaps in achievement and average GPA of white boys above the 50th percentile; "low" indicates schools that are below the 50th percentile. Sample statistics are weighted by baseline weights provided by the ELS. Two-tail test were conducted to compare means between samples in the low and high categories. ${ }^{*} p<0.05,{ }^{+} p<0.01$

in contrast to white boys. By eighth grade, point estimates indicate the emergence of an Asian American gender gap. By ninth grade, the gap becomes sizable and statistically significant. If fact, when the Asian American gender emerges, it is as large as the white gender gap. For example, in ninth grade, the Asian American gender gap is 0.36 standard deviations, and the white gender gap is 0.33 standard deviations.

The emergence of the Asian American gender gap at the transition to adolescence can be attributed to (1) the growth in achievement of Asian American girls in adolescence and (2) the fact that Asian American boys do not experience the same achievement growth as Asian American girls. Although Asian American boys still significantly outperform white boys in adolescence, they fall behind Asian American girls (and white girls). The findings suggest that Asian American boys accrue a smaller race premium relative to Asian American girls.

\section{Is There Evidence of Intersectionality?}

Figure 2 offers descriptive evidence that Asian American girls accrue a larger race premium than Asian American boys. Table 3 offers formal tests of whether race and gender effects are additive or interactive. Specifically, additive effects of race and gender mean that the race premium for girls in column 4 will be the same as the race premium for boys in column 5 . Interactive effects of race and gender mean that the race premium will be different for boys and girls. Columns 6 and 7 indicate whether the coefficient associated with the race-sex interaction terms are statistically significant in unadjusted and adjusted school-fixed effect models.

No significant interactive effects are found from kindergarten through eighth grade because the Asian American gender gap does not significantly emerge until 
Table 3: Predicted achievement scores by race and gender.

\begin{tabular}{|c|c|c|c|c|c|c|c|}
\hline & $\begin{array}{l}\text { Achieve } \\
\text { (Girls) }\end{array}$ & $\begin{array}{l}\text { Achieve } \\
\text { (Boys) }\end{array}$ & $\begin{array}{l}(3) \\
\text { Gender } \\
\text { Gap }\end{array}$ & $\begin{array}{c}(4) \\
\text { Race } \\
\text { Gap } \\
\text { (Girls) }\end{array}$ & $\begin{array}{l}(5) \\
\text { Race } \\
\text { Gap } \\
\text { (Boys) }\end{array}$ & $\begin{array}{c}(6) \\
\text { Race-Sex } \\
\text { Interact } \\
\text { (Unadjusted) }\end{array}$ & $\begin{array}{c}(7) \\
\text { Race-Sex } \\
\text { Interact } \\
\text { (Adjusted) }\end{array}$ \\
\hline \multicolumn{8}{|l|}{ Kindergarten } \\
\hline White & 0.21 & 0.09 & $0.12^{\dagger}$ & & & & \\
\hline Asian American & -0.04 & -0.06 & 0.02 & -0.24 & -0.15 & & \\
\hline \multicolumn{8}{|l|}{ Grade 1} \\
\hline White & 0.17 & 0.04 & $0.13^{\dagger}$ & & & & \\
\hline Asian American & 0.00 & -0.03 & 0.04 & -0.17 & -0.08 & & \\
\hline \multicolumn{8}{|l|}{ Grade 3} \\
\hline White & 0.16 & -0.04 & $0.20^{*}$ & & & & \\
\hline Asian American & 0.13 & -0.01 & 0.14 & -0.03 & 0.03 & & \\
\hline \multicolumn{8}{|l|}{ Grade 5} \\
\hline White & 0.09 & 0.01 & $0.08^{+}$ & & & & \\
\hline Asian American & 0.08 & -0.05 & 0.13 & -0.01 & -0.06 & & \\
\hline \multicolumn{8}{|l|}{ Grade 8} \\
\hline White & 0.14 & -0.04 & $0.18^{\dagger}$ & & & & \\
\hline Asian American & 0.28 & 0.10 & 0.18 & 0.13 & 0.14 & & \\
\hline \multicolumn{8}{|l|}{ Grade 9} \\
\hline White & 0.12 & -0.20 & $0.33^{+}$ & & & & \\
\hline Asian American & 0.41 & 0.05 & $0.36^{+}$ & 0.28 & 0.25 & + & $t$ \\
\hline \multicolumn{8}{|l|}{ Grade 10} \\
\hline White & 0.13 & -0.21 & $0.34^{+}$ & & & & \\
\hline Asian American & 0.44 & 0.02 & $0.42^{+}$ & 0.31 & 0.24 & + & + \\
\hline \multicolumn{8}{|l|}{ Grade 11} \\
\hline White & 0.14 & -0.21 & $0.35^{\dagger}$ & & & & \\
\hline Asian American & 0.43 & -0.03 & $0.46^{+}$ & 0.29 & 0.18 & + & + \\
\hline \multicolumn{8}{|l|}{ Grade 12} \\
\hline White & 0.18 & -0.24 & $0.42^{\dagger}$ & & & & \\
\hline Asian American & 0.40 & -0.08 & $0.48^{+}$ & 0.22 & 0.15 & t & t \\
\hline
\end{tabular}

Note: Predicted achievement scores are derived from unadjusted school-fixed effect regressions. The last two columns indicate if the race-sex interaction term in unadjusted and adjusted school-fixed effect models are statistically significant. Adjusted models control for family SES, generational status, single parenthood, number of siblings, and mother's age at first birth. ${ }^{*} p<0.10,{ }^{\dagger} p<0.05$ (two-tailed tests).

ninth grade. Once the Asian American gender gap emerges, the results show clear evidence of intersectionality. When the Asian American gender gap emerges in high school, we see that Asian American girls accrue a significantly larger race premium relative to Asian American boys. In ninth grade, the race premium for Asian American girls is only slightly higher than for Asian American boys. By 11th grade, the race premium for Asian American girls is 0.29 standard deviations and only 0.18 standard deviations for Asian American boys. These interactive effects remain significant after controlling for family SES, generational status, and family demographic characteristics. 


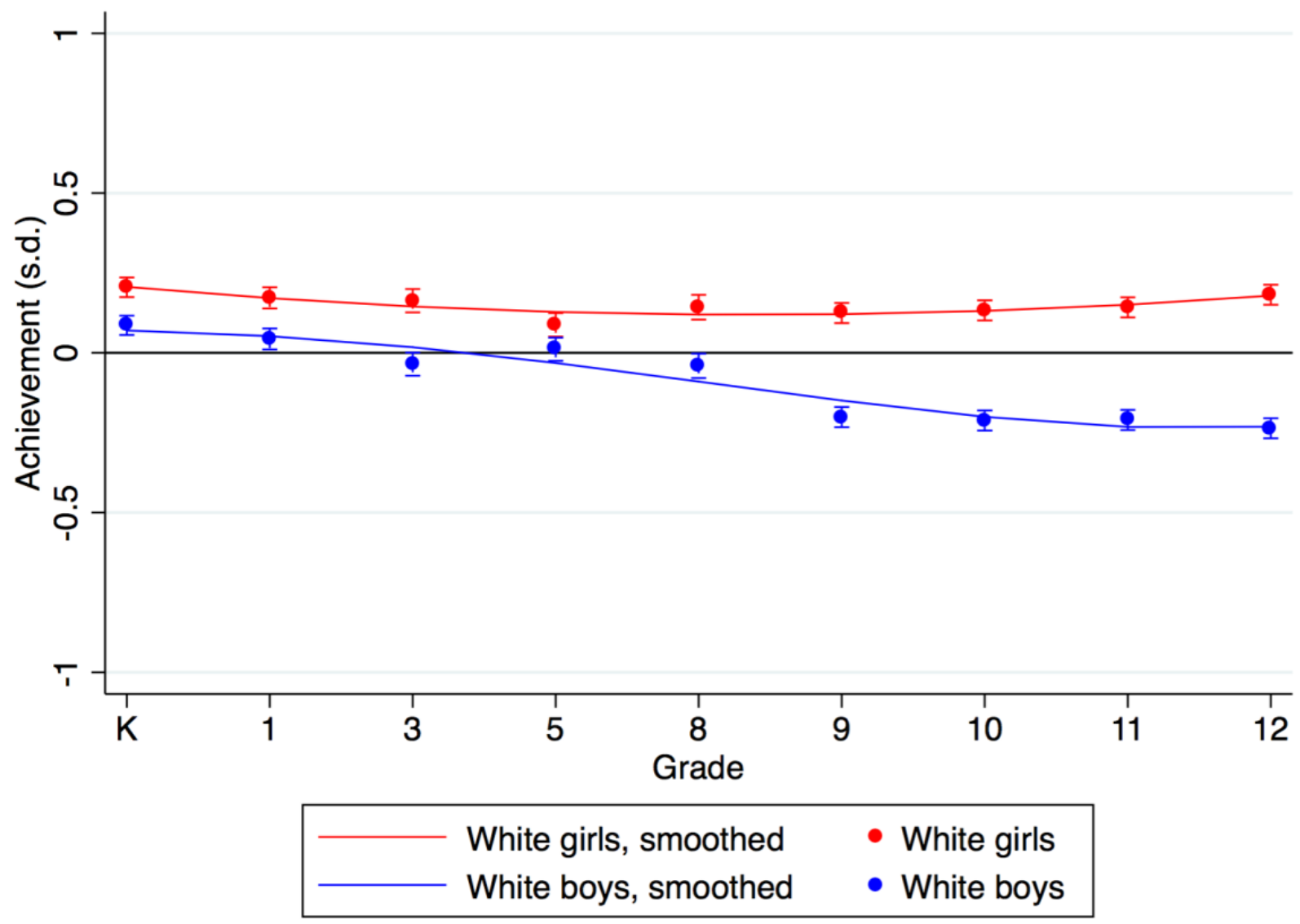

Figure 1: Gender gap in achievement among whites. Note: The figure plots the predicted achievement scores for white girls and boys from unadjusted school-fixed effect regressions. Kindergarten to eighth-grade scores come from the ECLS-K, and ninth- to 12th-grade scores come from the ELS.

\section{Ethnic Heterogeneity}

To examine ethnic heterogeneity, predicted 11th grade achievement scores by Asian ethnic subgroups are presented in Table 4 . The findings highlight important sources of ethnic variation. First, column 5 shows that Asian American girls outperform white girls across all ethnic subgroups, but column 6 shows that not all Asian American boys outperform white boys. East Asian and Filipino American boys experience the largest race premium over white boys. Column 6 shows that East Asian American boys outperform white boys by 0.29 standard deviations and Filipino American boys by 0.22 standard deviations. Southeast and South Asian American boys fare the worst and do not substantively differ from white boys. Southeast and South Asian American boys outperform white boys by 0.02 and 0.07 standard deviations, respectively.

Second, results disaggregated by ethnic subgroups also offer evidence of intersectionality. Southeast and South Asian American girls accrue a much larger racial premium relative to Southeast and South Asian American males. For example, 


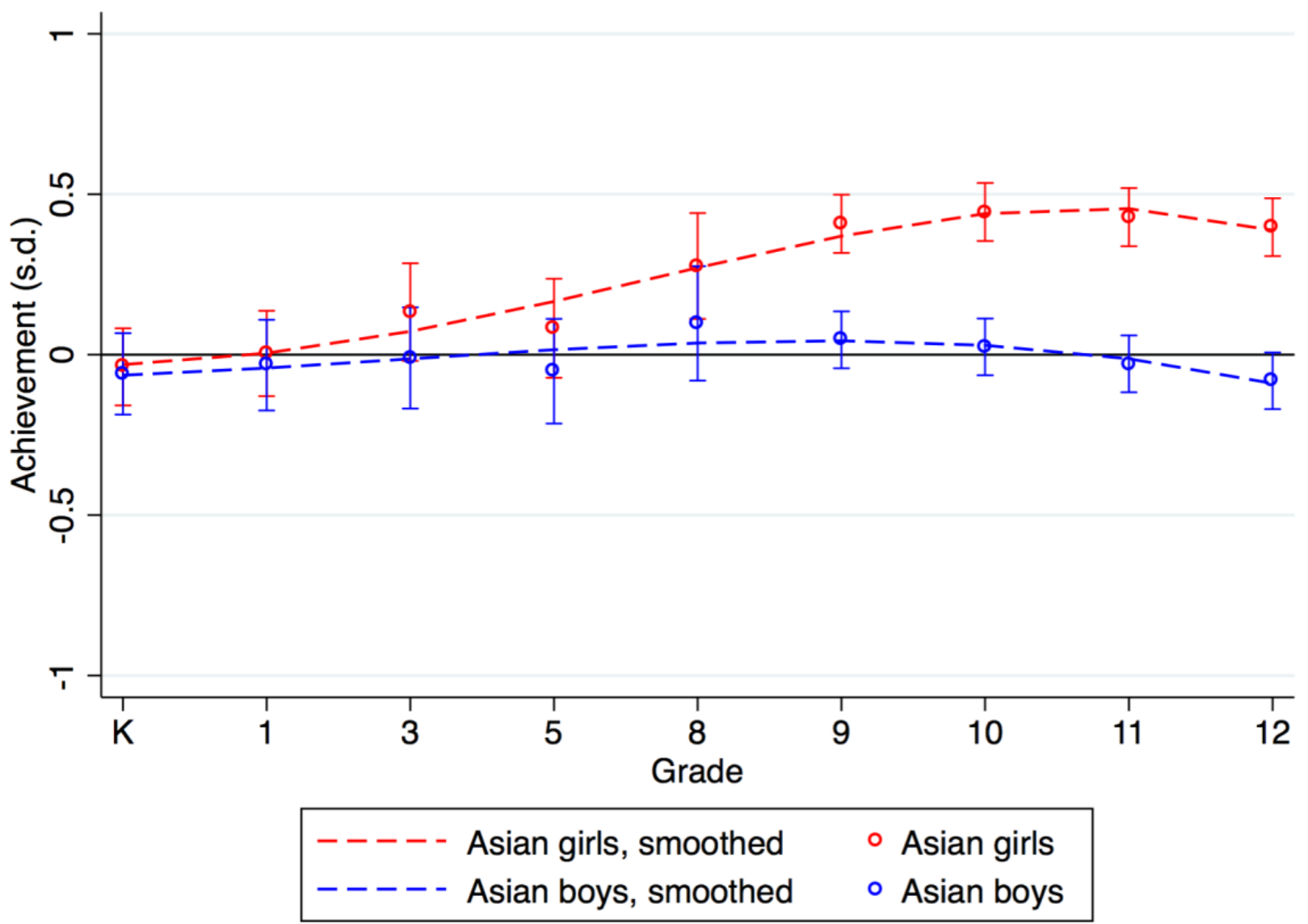

Figure 2: Gender gap in achievement among Asians. Note: The figure plots the predicted achievement scores for Asian American girls and boys from unadjusted school-fixed effect regressions. Kindergarten to eighth-grade scores come from the ECLS-K, and ninth- to 12th-grade scores come from the ELS.

Southeast Asian American girls accrue a racial premium of 0.31 standard deviations over white girls, whereas Southeast Asian American boys only accrue a racial premium of 0.02 standard deviations. East Asian American girls also accrue a larger racial advantage than East Asian American boys. The one exception is that Filipinos experience the same racial premium as Filipinas.

\section{School Effects and the Asian American Gender Gap}

The literature suggests that schools play a role in producing the gender gap. A first step is to test how the two measures of school environment-male-centric sports culture and the white gender gap in achievement-correlate to the Asian American gender gap in achievement. A second step is to consider the mechanisms that link the school environment to performance outcomes.

Table 5 present results from ordinary least square regressions predicting 11thgrade GPA among Asian American students. "More male sports $(=1)^{\prime \prime}$ indicates schools that have more male-only extracurricular sport activities than female-only 
Table 4: Predicted achievement scores by gender and Asian ethnic subgroups, 11th-grade GPA.

\begin{tabular}{|c|c|c|c|c|c|c|c|c|}
\hline & $\begin{array}{c}\text { (1) } \\
\text { Achieve } \\
\text { (Overall) }\end{array}$ & $\begin{array}{c}\text { Achieve } \\
\text { (Girls) }\end{array}$ & $\begin{array}{c}\text { (3) } \\
\text { Achieve } \\
\text { (Boys) }\end{array}$ & $\begin{array}{c}(4) \\
\text { Gender } \\
\text { Gap }\end{array}$ & $\begin{array}{c}\text { (5) } \\
\text { Race Gap } \\
\text { (Girls) }\end{array}$ & $\begin{array}{c}\text { (6) } \\
\text { Race Gap } \\
\text { (Boys) }\end{array}$ & $\begin{array}{c}(7) \\
\text { Race-Sex } \\
\text { Interact } \\
\text { (Unadjusted) }\end{array}$ & $\begin{array}{c}(8) \\
\text { Race-Sex } \\
\text { Interact } \\
\text { (Adjusted) }\end{array}$ \\
\hline White & -0.03 & 0.14 & -0.21 & 0.35 & & & & \\
\hline East Asian American & 0.30 & 0.54 & 0.10 & 0.44 & 0.40 & 0.29 & $*$ & $*$ \\
\hline Filipino American & 0.17 & 0.33 & 0.01 & 0.32 & 0.19 & 0.22 & & \\
\hline Southeast Asian American & 0.16 & 0.45 & -0.19 & 0.64 & 0.31 & 0.02 & * & $*$ \\
\hline South Asian American & 0.11 & 0.36 & -0.14 & 0.50 & 0.22 & 0.07 & $*$ & $*$ \\
\hline
\end{tabular}

Note: Columns 1, 2, and 3 present predicted achievement scores that are derived from unadjusted school-fixed effect regressions. Column 4 presents the gender gap in predicted achievement scores and is derived from subtracting columns 2 and 3 . Column 5 presents the race premium between girls from each Asian ethnic subgroup and white girls. Column 6 presents the race premium between boys from each Asian ethnic subgroup and white boys. The last two columns indicate if the race-sex interaction term in unadjusted and adjusted school-fixed effect models are statistically significant. Adjusted models control for family SES, generational status, single parenthood, number of siblings, and mother's age at first birth. ${ }^{*} p<0.05$ (two-tailed tests).

sport activities. The "white gender gap" is a continuous variable indicating the difference in average GPA between white boys and white girls in each school. I present the estimated main effects of school environment, gender, and statistical interactions between schools and genders. Model 1 estimates the effect of schools on the gender gap, controlling only for prior performance (ninth-grade GPA). Model 2 includes a control for students' academic engagement. Model 3 introduces all additional controls for family SES, demographic characteristics, and school characteristics.

Model 1 shows that Asian American boys' grades are negatively associated with male-centric sports culture, but this has no effect on girls' performance. When students' academic engagement is included in regressions in Model 2, the estimated effect of male-centric sports reduces by half from a -0.169 standard deviation decline in GPA to a -0.085 standard deviation decline in GPA. This reduction in the point estimate indicates that at least some of the association between school sports culture and boys' academic performance is working through boys' academic engagement and orientation toward schoolwork. Model 3 introduces all other individual-, family-, and school-level characteristics. The point estimates do not change substantially from Model 2 to Model 3.

The findings using the white gender gap in performance as a proxy for the dominant gender norms in place at schools parallels the findings presented above. Model 4 shows that Asian American boys' grades are reduced by -0.107 standard deviations for each standard deviation increase in the white gender gap. The white gender gap is not significantly associated with the grades of Asian American girls. When students' academic engagement is introduced in Model 5, the effect of the white gender gap on Asian American boys is no longer statistically significant.

Overall, the results show how the school environment-male-centric sports culture and the white gender gap-is negatively associated with Asian American boys' grades but not Asian American girls' grades. These results are consistent with studies that show that boys' achievement is more sensitive to the school environment than girls' achievement (Legewie and DiPrete 2012). The results also indicate that the link between the school environment and boys' academic 
Table 5: Effects of schools on 11th-grade GPA of Asian American students, ELS.

\begin{tabular}{lcccccc}
\hline Variable & Model 1 & Model 2 & Model 3 & Model 4 & Model 5 & Model 6 \\
\hline Female & $0.145^{\dagger}$ & $0.125^{*}$ & $0.138^{*}$ & $0.151^{\dagger}$ & $0.160^{\dagger}$ & $0.174^{\dagger}$ \\
& $(2.890)$ & $(2.500)$ & $(2.590)$ & $(3.030)$ & $(3.170)$ & $(3.270)$ \\
More male sports (=1) & $-0.169^{\dagger}$ & $-0.085^{*}$ & $-0.082^{*}$ & & & \\
& $(3.010)$ & $(2.790)$ & $(2.510)$ & & & \\
More male sports x female & 0.082 & 0.103 & 0.101 & & & \\
& $(1.180)$ & $(1.480)$ & $(1.400)$ & & & \\
White gender gap & & & & $-0.107^{*}$ & -0.081 & -0.042 \\
& & & & $(1.710)$ & $(1.670)$ & $(0.620)$ \\
White gender gap x female & & & & 0.088 & 0.056 & 0.046 \\
& -0.049 & $-0.105^{*}$ & 0.038 & $-0.083^{*}$ & $-0.170^{\dagger}$ & -0.016 \\
Constant & $(1.190)$ & $(2.550)$ & $(0.170)$ & $(1.960)$ & $(4.170)$ & $(0.070)$ \\
& Yes & Yes & Yes & Yes & Yes & Yes \\
Control for ninth-grade GPA & No & Yes & Yes & No & Yes & Yes \\
Control for academic engagement & No & No & Yes & No & No & Yes \\
All other controls & 0.54 & 0.58 & 0.6 & 0.54 & 0.58 & 0.59 \\
$R^{2}$ & & & & & & \\
\hline
\end{tabular}

Note: $N=1,257$. Model 1 only controls for ninth-grade GPA. Model 2 includes teacher reports of students' academic engagement in 10th grade. Model 3 includes all other controls for family SES, generational status, single parenthood, number of siblings, mother's age at first birth, parents' educational expectations, and school contexts. The dependent variable is measured in terms of standard deviations. Standard errors are adjusted for clustering at the school level. ${ }^{*} p<0.05,{ }^{\dagger} p<0.01$ (two-tailed tests) .

performance is at least partially working through academic engagement and proschool behaviors.

\section{Discussion}

This study leverages variation in immigration experiences and gender expectations and across developmental stages in gender-identity formation to explore the role of norms in shaping the gender gap in academic performance from kindergarten through high school. Building on the research in gender studies, adolescent development, and educational stratification, I describe differences in the emergence and evolution of the gender gap in achievement between whites and Asian Americans, examine the role of school environment and peer culture in shaping the Asian American gender gap that emerges in adolescence, and explore potential explanations for racial differences in the gender gap.

I find that no gender gap in achievement exists among Asian Americans in early-to-middle childhood; the Asian American gender gap only emerges at the transition to adolescence. These results for Asian Americans stand in stark contrast to the results for white students. For white students, a sizable and persistent gender gap in achievement already exists at the start of kindergarten. When the gender gap emerges for Asian Americans, we see that the gap is attributable to (1) the large and growing achievement successes of Asian American girls relative to everyone else 
(including white girls) and (2) the fact that Asian American boys do not experience the same academic successes as Asian American girls.

I speculate that a combination of factors related to the immigrant experience and potential differences in cultural understandings of education and masculinity may account for observed differences in the emergence of the gender gap between whites and Asian Americans. Immigrant optimism, high parental expectations, children's belief that their academic achievement redeems parental sacrifice, stereotype promise, and more fluid concepts of masculinity may serve as protective factors for Asian American boys and help bolster their academic performance relative to their white male peers. These protective factors, however, may wane at the transition to adolescence. Adolescence is a period when many adolescent boys turn away from families and communities to establish autonomy. During this period, Asian American boys may begin modeling emerging gender identities after the masculine ideals of the dominant culture. Additionally, model-minority stereotypes are gendered and stigmatize Asian American boys more than Asian American girls. As immigrant boys of color, Asian American boys confront more negative stereotypes and face greater discrimination than Asian American girls, making them more likely to shed their racial identities and resist model-minority stereotypes by becoming more academically disengaged.

I also find evidence that school environments and peer norms play a role in generating the Asian American gender gap. The Asian American gender gap is larger in schools where the dominant peer culture valorizes athleticism and normalizes boys' underachievement. I find evidence that a mechanism through which the school environment affects the gender gap is lowering the academic engagement of Asian American boys. These findings contribute to a growing body of research showing that schools are agents of gender stratification that channel concepts of masculinity into the learning environment (Legewie and DiPrete 2012, 2014). The results indicate that schools where boys are expected to underachieve are environments that codify underachievement as features of masculinity and create peer cultures that perceive pro-school behaviors and attitudes as deviations from masculine standards. Conversely, schools where boys are expected to excel are environments that foster boys' achievement by enhancing their commitment to academics and promote smaller disparities between boys and girls.

The study reveals interesting sources of ethnic subgroup variation in gender patterns of achievement that highlight potential avenues for future research. Specifically, the results show important sources of ethnic heterogeneity in the Asian American gender gap in achievement in high school. Whereas Asian American girls outperform white girls across all ethnic subgroups, Asian American boys do not uniformly outperform white boys. East Asian and Filipino American boys significantly outperform white boys in high school, but Southeast and South Asian American boys are not markedly different than white boys in terms of their high school GPA. These findings suggest that the protective factors that help bolster the academic success of East Asian and Filipino American boys do not protect Southeast and South Asian American boys. Although existing studies comparing Asian American and hegemonic concepts of masculinity in the United States show that Asian American understandings of masculinity are more fluid, few studies 
have examined variation in gender expectations across Asian ethnic groups in the United States. Therefore, it is unknown to what extent ethnic variation in standards of masculinity account for why South and Southeast Asian American boys seem to accrue no racial premium in academic achievement. Future work can focus on describing variation in masculine standards across Asian ethnic subgroups and understanding how potential variation in gender expectations might account for variation in the gender gap in achievement among Asian American youth.

\section{Notes}

1 Linear regressions predicting academic achievement by using the pooled sample of Asian American and white students were also estimated. The gender gaps in achievement when using the pooled estimates are slightly larger than the gender gap in achievement from school-fixed effect estimates, but the overall patterns are similar. Within-school estimates are presented because they serve as more conservative estimates of the achievement gap.

2 In theory, $\beta_{3}<0$ is also a possible outcome. However, there is no evidence to suspect that Asian American girls should accrue a lower race premium than Asian American boys.

\section{References}

Archer, Louise, Simon D. Pratt, and David Phillips. 2001. "Working-Class Men's Constructions of Masculinity and Negotiations of (Non)Participation in Higher Education." Gender and Education 13:431-49. https ://doi .org/10.1080/09540250120081779.

Billson, Janet Mancini. 1995. Keepers of the Culture: The Power of Tradition in Women's Lives. San Francisco, CA: Jossey-Bass.

Brown, B. Bradford, Donna R. Clasen, and Sue A. Eicher. 1986. "Perceptions of Peer Pressure, Peer Conformity Dispositions, and Self-Reported Behavior among Adolescents." Developmental Psychology 22:521. https : //doi .org/10.1037/0012-1649.22 .4.521.

Catsambis, Sophia. 2005. “The Gender Gap in Mathematics: Merely a Step Function?" Pp. 220-45 in Mind the Gap: Gender Differences in Mathematics, edited by A. M. Gallagher and J. C. Kaufman. Cambridge, UK: Cambridge University Press.

Chen, Anthony. 1999. "Lives at the Center of the Periphery: Chinese American Masculinities and Bargaining with Hegemony." Gender $\mathcal{E}$ Society 13:584-607. https : //doi .org/10 . $1177 / 089124399013005002$.

Chua, Peter, and Dune C. Fujino. 1999. "Negotiating New Asian-American Masculinities: Attitudes and Gender Expectations." The Journal of Men's Studies 7:391-413. https: //doi.org/10.3149/jms.0703.391.

Coleman, James S. 1966. Equality of Educational Opportunity. Washington, DC: Office of Education, U.S. Department of Health, Education, and Welfare.

Connell, Robert W., and James W. Messerschmidt. 2015. "Hegemonic Masculinity: Rethinking the Concept." Gender E Society 19:829-59. https://doi.org/10.1177/ 0891243205278639.

Dasgupta, Shamita Das. 1998. "Gender Roles and Cultural Continuity in the Asian Indian Immigrant Community in the US." Sex Roles 38:953-74. https://doi .org/10.1023/A: 1018822525427. 
DiPrete, Thomas A., and Claudia Buchmann. 2013. The Rise of Women: The Growing Gender Gap in Education and What It Means for American Schools. New York, NY: Russell Sage Foundation.

DiPrete, Thomas, and Jennifer Jennings. 2012. "Social and Behavioral Skills and the Gender Gap in Early Educational Achievement." Social Science Research 41:1-15. https://doi. org/10.1016/j.ssresearch.2011.09.001.

Downey, Doug, and Anastasia S. Vogt Yuan. 2005. "Sex Differences in School Performance During High School: Puzzling Patterns and Possible Explanations." Sociological Quarterly 46:299-321. https://doi.org/10.1111/j.1533-8525.2005.00014.x.

Eng, D. L. 2001. Racial Castration: Managing Masculinity in Asian American. Durham, NC: Duke University Press. https://doi.org/10.1215/9780822381020.

England, Paula. 2010. "The Gender Revolution: Uneven and Stalled." Gender E Society 24:149-66. https://doi.org/10.1177/0891243210361475.

Epstein, Debbie. 1998. "Real Boys Don't Work: Underachievement, Masculinity and the Harassment of Sissies." Pp. 96-108 in Failing Boys? Issues in Gender and Achievement, edited by D. Epstein, J. Elwood, V. Hey, and J. Maw. Buckingham, UK: Open University Press.

Espiritu, Yen Le. 2001. “We Don't Sleep around Like White Girls Do: Family, Culture, and Gender in Filipina American Lives." Signs 26:414-40. https ://doi .org/10.1086/ 495599.

Espiritu, Yen Le. 2008. Asian American Women and Men: Labor, Laws, and Love. Lanham, MD: Rowman \& Littlefield.

Gilligan, Carol. 1996. "The Centrality of Relationship in Human Development: A Puzzle, Some Evidence, and a Theory." Pp. 237-62 in Development and Vulnerability in Close Relationships, edited by G. Noam and K. Fischer. Mahwah, NJ: Lawrence Erlbaum Associates.

Goyette, Kimberly, and Yu Xie. 1999. "Educational Expectations of Asian American Youths: Determinants and Ethnic Differences." Sociology of Education 72:22-36. https://doi. org/10.2307/2673184.

Hill, Jennifer, and Mary Ellen Lynch. 1983. “The Intensification of Gender-Related Role Expectations During Early Adolescence." Pp. 201-28 in Girls at Puberty: Biological and Psychosocial Perspectives, edited by J. Brooks-Gunn and A. Peterson. New York, NY: Plenum. https://doi .org/10.1007/978-1-4899-0354-9_10.

Hsin, Amy, and Yu Xie. 2014. “Explaining Asian Americans' Academic Advantage over Whites." Proceeding of the National Academy of Sciences 11:8416-21. https ://doi .org/10. 1073/pnas. 1406402111.

Jackson, Carolyn, and Steven Dempster. 2009. “'I Sat Back on My Computer ... with a Bottle of Whisky Next to Me': Constructing 'Cool' Masculinity through 'Effortless' Achievement in Secondary and Higher Education." Journal of Gender Studies 18: 341-56. https://doi.org/10.1080/09589230903260019.

Jencks, Christopher, and Susan E. Mayer. 1990. "The Social Consequences of Growing up in a Poor Neighborhood." Pp. 111-86 in Inner-city Poverty in the United States, edited by L. E. Lynn and M. G. H. McGeary. Washington, DC: National Academy Press.

Kao, Grace, and Marta Tienda. 1998. "Educational Aspirations of Minority Youth." American Journal of Education 106:349-84. https ://doi .org/10.1086/444188.

Lee, Jennifer, and Min Zhou. 2015. The Asian American Achievement Paradox. New York, NY: Russell Sage Foundation. 
Legewie, Joscha, and Thomas A. DiPrete. 2012. "School Context and the Gender Gap in Educational Achievement." American Sociological Review 77:463-85. https://doi .org/ 10.1177/0003122412440802.

Legewie, Joscha, and Thomas A. DiPrete. 2014 "The High School Environment and the Gender Gap in Science and Engineering." Sociology of Education 87:259-80. https://doi . org/10.1177/0038040714547770.

Lei, Joy L. 2003. "(Un)Necessary Toughness?: Those 'Loud Black Girls' and Those 'Quiet Asian Boys."' Anthropology E Education Quarterly 34:158-81. https : //doi .org/10.1525/ aeq.2003.34.2.158.

Liu, Airan, and Yu Xie. 2016. "Why Do Asian Americans Academically Outperform Whites? - The Cultural Explanation Revisited." Social Science Research 58:210-26. https://doi . org/10.1016/j.ssresearch.2016.03.004.

Lu, Alexander, and Y. Joel Wong. 2013. "Stressful Experiences of Masculinity among US-born and Immigrant Asian American Men." Gender E Society 27:345-71. https: //doi.org/10.1177/0891243213479446.

McCall, Leslie. 2005. “The Complexity of Intersectionality." Signs 30:1771-800. https: //doi.org/10.1086/426800.

Mickelson, Roslyn Arlin. 1989. "Why Does Jane Read and Write so Well? The Anomaly of Women's Achievement." Sociology of Education 47-63. https://doi .org/10.2307/ 2112823.

Miller, Jean Baker. 1991. “The Development of Women's Sense of Self." Pp. 11-26 in Women's Growth in Connection: Writings from the Stone Center, edited by J. V. Jordan, A. G. Kaplan, J. B. Miller, I. P. Stiver, and J. L. Surrey. New York, NY: Guilford Press.

Morris, Edward W. 2008. "'Rednecks,' 'Rutters,' and Arithmetic: Social Class, Masculinity, and Schooling in a Rural Context." Gender E Society 22:728-51. https ://doi .org/10 . $1177 / 0891243208325163$.

Morris, Edward W. 2011. “Bridging the Gap: 'Doing Gender', 'Hegemonic Masculinity', and the Educational Troubles of Boys." Sociology Compass 5:92-103. https://doi.org/10. $1111 / \mathrm{j} .1751-9020.2010 .00351 . \mathrm{x}$.

Pascoe, C. J. 2007. Dude, You're a Fag: Masculinity and Sexuality in High School. Berkeley, CA: University of California Press.

Perkins R., B. Kleiner, S. Roey, and J. Brown. 2004. The High School Transcript Study: A Decade of Change in Curriculum and Achievement, 1990-2000. Washington, DC: National Center for Education Statistics.

Qin, Desiree Baolian. 2009. “Being 'Good' or Being 'Popular': Gender and Ethnic Identity Negotiations of Chinese Immigrant Adolescents." Journal of Adolescent Research 24:37-66. https://doi .org/10.1177/0743558408326912.

Ridgeway, Cecilia L., and Shelley J. Correll. 2004. “Unpacking the Gender System: A Theoretical Perspective on Gender Beliefs and Social Relations." Gender E Society 18:51031. https://doi .org/10.1177/0891243204265269.

Rumbaut, Ruben G. 1997. “Ties That Bind: Immigration and Immigrant Families.” Pp. 3-46 in Immigration and the Family: Research and Policy on US Immigrants, edited by A. Booth, A. C. Crouter, and N. Landale. Mahwah NJ: Lawrence Erlbaum.

Sakamoto, Arthur, Kimberly A. Goyette, and ChangHwan Kim. 2009. "Socioeconomic Attainments of Asian Americans." Annual Review of Sociology 35:255-76. https://doi . org/10.1146/annurev-soc-070308-115958. 
Steinberg, Laurence, and Susan B. Silverberg. 1986. "The Vicissitudes of Autonomy in Early Adolescence." Child Development 1:841-51. https://doi .org/10.2307/1130361.

Suárez-Orozco, Carola, and Desirée Baolian Qin. 2006. “Gendered Perspectives in Psychology: Immigrant Origin Youth." International Migration Review 40:165-98. https: //doi.org/10.1111/j.1747-7379.2006.00007.x.

Sung, Betty Lee. 1987. The Adjustment Experience of Chinese Immigrant Children in New York City. New York, NY: Center for Migration Studies.

Tach, Laura, and George Farkas. 2006. "Learning-Related Behaviors, Cognitive Skills, and Ability Grouping When Schooling Begins." Social Science Research 35:1048-79. https : //doi.org/10.1016/j.ssresearch.2005.08.001.

Talbani, Aziz, and Parveen Hasanali. 2000. "Adolescent Females between Tradition and Modernity: Gender Role Socialization in South Asian Immigrant Culture." Journal of Adolescence 23:615-27. https : //doi .org/10.1006/jado.2000.0348.

Tran, Van C. 2016. "Ethnic Culture and Social Mobility among Second-Generation Asian Americans." Ethnic and Racial Studies 39:2398-403. https://doi .org/10.1080/ 01419870.2016 .1200740$.

Ueno, Koji, and Summer McWilliams. 2010. "Gender-Typed Behaviors and School Adjustment." Sex Roles 63:580-91. https://doi .org/10.1007/s11199-010-9839-6.

West, Candace, and Don H. Zimmerman. 1987. "Doing Gender." Gender and Society 1:125-51. https://doi.org/10.1177/0891243287001002002.

Wong, Y. Joel, Jesse Owen, Kimberly K. Tran, Dana L. Collins, and Claire E. Higgins. 2012. "Asian American Male College Students' Perceptions of People's Stereotypes about Asian American Men." Psychology of Men E Masculinity 13:75-88. https : //doi .org/10.1037/ a0022800.

Xie, Yu, and Kimberlee A. Shauman. 2003. Women in Science. Cambridge, MA: Harvard University Press.

Yavorsky, Jill, and Claudia Buchmann. 2018. "Gender Typicality and Academic Achievement among American High School Students." Unpublished manuscript.

Yip, T., and A. Fuligni. 2002. "Daily Variation in Ethnic Identity, Ethnic Behaviors, and Psychological Wellbeing among American Adolescents of Chinese Descent." Child Development 73:1557-72. https://doi .org/10.1111/1467-8624.00490.

Zhou, Min, and Carl L. Bankston III. 2001. "Family Pressure and the Educational Experience of the Daughters of Vietnamese Refugees." International Migration 39:133-51. https: //doi.org/10.1111/1468-2435.00165.

Acknowledgments: The author would like to thank Yu Xie, Kate Choi, Sophia Catsambis, and Lizandra Friedland for commenting on earlier versions of this work. All remaining errors are strictly the responsibility of the author.

Amy Hsin: Department of Sociology, Queens College, City University of New York. E-mail: amy.hsin@qc.cuny.edu. 